\title{
LA QUIEBRA DEL ESTADO MODERNIZADOR
}

\author{
EDUARDO RUIZ ABELLÁN \\ Titular interino de Universidad \\ de Ciencia Política
}

\section{INTRODUCCIÓN}

La aceleración de los procesos históricos y su multiplicación a la altura de este fin de siglo está empezando a afectar seriamente la capacidad de mantener con sosiego la atención que el estudio de todo hecho social requiere.

En estos tiempos, ciertamente apasionantes, que nos ha sido dado vivir, lo que hoy se nos presenta como el «tema» por antonomasia, es muy probable que al día siguiente, por causa de nuevos sucesos, haya perdido, si no interés, sí, al menos, una dosis importante de actualidad. A todo lo cual, evidentemente, no es ajeno el papel de los medios de comunicación en la construcción social de la realidad. Lo anteriormente expuesto, con ser, a mi juicio, verdadero, no debe, sin embargo, inducir al estudioso ni a la pasividad ni al desconcierto, antes, al contrario, parece obligación propia de su estatus «serenar» los acontecimientos y descubrir en ellos, en la medida de lo posible, las líneas profundas de sentido que permiten su adecuada explicación.

Siguiendo esta orientación y en el momento en que estas líneas se escriben, 1992, creo que aparece nítido a nuestros ojos la inserción de nuestro tiempo en una época agónica, propia para el balance, la crítica y la revisión que, en términos muy generales, parece coincidir con la terminación de «lo Moderno» y la transición hacia nuevas visiones del mundo y de la vida que provisionalmente podemos, con Topynbee y otros, denominar Postmodernidad.

Entre las diversas manifestaciones que se suceden en esta época, no es quizás la de menor porte la crisis de su forma política característica: el Estado. Quisiera recordar a Bell como autor de la frase que considera que «el Estado se ha vuelto demasiado grande para resolver los problemas pequeños y demasiado pequeño para resolver los grandes problemas». Otros autores, en la misma línea, pero atenuando las consecuencias, prefieren hablar mejor de crisis en las formas de desarrollo estatales, ante que de problemas en la matriz originaria.

Sea de ello lo que fuese, lo cierto es que el agotamiento de la «modernidad tecnocrática» (Ballesteros, 1989, p. 125) va acompañado desde hace algún tiempo de diversos enfoques críticos frente a las concretas formas estatales de nuestros días. 
En este contexto, no puede parecer extraño que se hable de «déficit de legitimación en las formas estatales del capitalismo tardío (Habemas), de fin del Estado Redentor (Touraine) o de quiebra del Estado Modernizador (Halliday).

Esta situación no podía por menos de repercutir en los respectivos aparatos de apoyo intelectual o ideológico que, como en el caso del Welfare State, refluyen hacia ya conocidas pero no por ello aproblemáticas aguas neoliberales; en los otrora denominados «Estados de socialismo real» se ven implicados en el descrédito del comunismo como doctrina de salvación y en los Estados surgidos de la descolonización oscilan, especialmente en el mundo islámico, entre el modelo fundamentalista y un autoritarismo carente de paradigmas definidos o en el peor de los casos, como en el Africa profunda, en la vuelta al tribalismo.

Limitándonos a los Estados modernizados quizás sea conveniente recordar cómo los procesos generales de descolonización hicieron posible, desde el fin de la II Guerra Mundial, el surgimiento de nuevas formas estatales con vocación de convertirse en sujetos de la Historia. Las esperanzas en una puesta al día de las respectivas estructuras sociales y económicas parecían acompañar, con buenos augurios, el parto muchas veces doloroso y aún sangriento, de los nuevos Estados nacionales. Se creyó, tanto por las metrópolis descolonizadoras como por las nuevas élites dirigentes, que, de manera semejante al proceso de crecimiento de los seres humanos, el desarrollo de estas nuevas comunidades debía dirigirse mediante una suerte de «imitatio» hacia los modelos encarnados por las sociedades desarrolladas de Occidente que, al menos en aquellos momentos, parecían plenamente conseguidos. Lograr los niveles de vida culturales, sociales y económicos de las sociedades desarrolladas mediante la puesta en marcha de los paradigmas modernizadores, parecía una meta fácil de conseguir aunando el fervor nacionalista al mítico impulso del «Progreso».

La consecución de aquellos fines implicaba la utilización de todos los medios que «racionalmente» fuesen eficaces. El «Proyecto modernizador» conllevaba necesariamente la puesta en marcha de procesos de urbanización, diferenciación estatal, secularización, industrialización y alfabetización cuyos efectos combinados habían de conducir «indefectiblemente» a las «sociedades de la abundancia» de Occidente.

A la vuelta de unos pocos años nos habíamos de encontrar, en suma, con estas nuevas realidades: la consagración de los derechos del hombre en el plano jurídico. La consecución de la Revolución Industrial y Científica en el terreno técnico. La adopción de las instituciones democráticas reguladoras de los conflictos sociales en el campo político y en el mundo de la vida con un «nuevo hombre» desligado de las ataduras tradicionales y plenamente disponible para las tareas modernizadoras. Corolario de todo lo anterior había de ser la inserción de estos flamantes sujetos del Derecho Internacional en un nuevo y flexible orden económico mundial.

El final de los años setenta ha supuesto para todos los países surgidos de la 
descolonización, especialmente en el Norte de Africa a los que, en principio, se contrae este análisis, el amargo despertar de un bello sueño. Como señala J. J. Chevallier (Introducción a Lamchichi, 89) «La voluntad de transposición por 'fascinación beata' del modelo occidental habría fracasado tanto en el terreno económico (deuda exterior, impotencia ante el subdesarrollo, marginalización y exclusión de amplias capas de población), como en el político, en el que la fragilidad de la sociedad civil coincidiría con la omnipotencia de un Estado autoritario y represivo».

Este fracaso que, en mayor o menor medida, puede predicarse de todos los países del Mediterráneo musulmán y del Maghreb en particular, no sólo podría explicarse por la inadecuación que supuso la aplicación de un modelo que habría ignorado el fondo cultural propio y la identidad islámica fundamental de estas sociedades (Lamchichi, 1989, p. 8) sino también por un defecto que se halla en la propia raíz del proyecto modernizador: la insuficiencia de la razón instrumental para poder aplicar con éxito cualquier tipo de técnicas con independencia de las representaciones simbólicas o de la escala normativa subyacente. La distinción positivista entre hechos y valores, el desprecio o la exclusión de los mismos y su exilio al mundo de lo precientífico o irracional se unen, también, al síndrome de este fracaso, que sin embargo, quedaría incompleto sin aludir a lo que, en pura concordancia con una visión científica técnica de la política, tenía de «experimento» la aplicación de los proyectos de «desarrollo» a los emergentes Estados descolonizados.

Por todo ello, la quiebra de estos Estados no es sólo el fracaso, trágico en tantos casos, de unas sociedades «adolescentes» sino también, y por eso no es casual su coincidencia en el tiempo, la exteriorización de la crisis o de la frustración (Habermas), del presupuesto teórico subyacente: la «Modernidad», lo que, en última instancia, no es más que secuela inevitable» del fracaso del mito del Progreso (Fernández Carvajal, 1991, p. 24) basado en una pura racionalidad científica (Innerarity, 1990, p. 236).

El juicio que «ex post facto» ha merecido la modernización tecnocrática es concluyente en cuanto a sus secuelas de injusticia e inhumanidad: «Por doquier, en el tercer mundo, alló donde se ha impuesto la modernidad, la sociedad se ha dividido en dos comunidades opuestas a las que todo separa: la sensibilidad, el modo de vida, la ética, las relaciones con la naturaleza, el Estado, la Patria, el poder, la historia y las aspiraciones. Una de ellas minoritaria, florece en la prosperidad, la otra mayoritaria está destinada a la muerte lenta y al aislamiento» (B. Ghalioum, cit. por Ballesteros, 1989, p. 126).

El fracaso de este experimento modernizador ha solido ser explicado tanto en términos de «dependencia» cuanto de «incapacidad para el desarrollo». En el primer caso la imputación de responsabilidades se dirige hacia un «Centro» (antigua o nueva metrópoli) con el que se mantendrían relaciones de tipo subordinado caracterizadas por la complementariedad y la dominación. En el segundo caso, la 
ineficacia resultaría de la ineptitud de las «Elites» modernizadoras para poner en marcha con éxito los procesos sociales requeridos (Sami Nair. Le Tiers Monde dedublé. Connaisances du Politique, 1990, p. 233).

Sea de ello lo que fuere, lo cierto es que ninguno de los grandes objetivos asignados como umbrales a franquear por los Estados modernizadores han podido ser suficientemente traspasados. La industrialización eficaz, la democracia política y el mejoramiento en los niveles de vida de amplias capas de población rural o urbana, se han revelado como objetivos inalcanzables.

De acuerdo con los datos disponibles (Cidob, 1990), una comparación entre el IDH (Indice de Desarrollo Humano: P.I.B. per cápita, esperanza de vida y tasa de alfabetismo) de los países situados en el Norte y Sur del Mediterráneo, revela que mientras Francia, Italia y España, en una escala de 1 (Niger) a 150 (Japón), ocupan respectivamente los puestos 123,117 y 115, Túnez, Argelia y Marruecos ocupan los lugares 60,57 y 44 de la escala a nivel mundial.

El resultado de tal frustración es doble: sociedades estructuradas dualmente y dirección política encomendada a Estados «Neo-Absolutistas» (S. Nair, 1990, p. 249). En efecto, para este autor el sistema social de los países del tercer mundo en general y del Maghreb en particular podría subdividirse en dos grandes ejes estructurales:

a) Un primer eje que se podría denominar como «subsistema integrado» y por tanto articulado en el mundo de la producción y

b) Un segundo eje que es el «campo de la marginalidad» y en el que predomina una «cultura de la sobrevivencia».

Esta campo de la marginalidad, no hay que decir que muy numeroso, es el que, en parte, ha dado lugar a la génesis de Estados fuertes no democráticos en esta región, lo que se explica por la consolidación de la escisión entre los dos subsistemas sociales antagónicos.

Hay, no obstante, que destacar que, en general, y frente a la «lógica revolucionaria» occidental, la respuesta a esta situación, en muchos casos, ha sido la «Revuelta» en el sentido dado a esta palabra por Octavio Paz (Ballesteros, 1989, p. 125) y que en tanto que alternativa a las formas de modernización occidentales se afirmaría en el arrraigo en la tradición cultural y religiosa (Kepel) y la defensa de la propiedad comunal en unos casos o de la identidad cultural y de las formas básicas de vida en otros: Bereberes de Argelia, Tuareg de Mali o Libia, etc.

Dadas estas premisas no debe extrañar la incapacidad de la lógica tecnocrática moderna e incluso de algún sector de la postomoderna paar entender primero y encarar después las consecuencias de este fracaso que con sus inevitables secuelas de inestabilidad amenaza el flanco sur de esta especie de «Arcadia Feliz» que a los ojos de muchos de nuestros contemporáneos empieza a parecer la Europa desarrollada y, casi, consolidada en Maastrich. 
Si a todo lo expuesto añadimos el peso específico que el componente religioso y aún el mítico, tienen en los plantamientos políticos de los pueblos islámicos, no es de extrañar que uno de los líderes europeos más conocidos: H. Smiht confesara paladinamente que: «apenas entendemos nada del Islam» para concluir afirmando: «Si nosotros en Occidente no hacemos serios esfuerzos para entender y tratar las masas islámicas que se multiplican mucho más rápidas que la población de Europa y América, entraremos en una etapa peligrosa» (Rev. Política Exterior, nํㅜ 19, 1991, p. 37).

En seguimiento de esta sugerencia parece oportuno dirigir nuestra atención de manera específica a la crisis del Estado modernizador en el Maghreb y ello porque los escasos kilómetros que nos separan de sus costas y la intensidad de sus problemas parecen razónes más que suficientes para superar el etnocentrismo que habitualmente aqueja a nuestro enfoque de los asuntos políticos.

\section{BALANCE DEL PARADIGMA MODERNIZADOR}

La necesidad sentida con carácter urgente a partir de los años cincuenta de obtener de las experiencias de la historia las enseñanzas suficientes con las que hacer frente a los retos que a partir de este momento suscitan los nuevos Estados en vías de consolidación (Pasquino, 1974, p. 47), explica que al abrirse la década de los setenta, la política comparada estuviera instalada en la teoría de la modernización como eje intelectual de coordenadas (López Pina, 1972, p. 426) con el fin de «desarrollar hipótesis que pudiesen ser puestas a prueba en investigaciones sobre el terreno en países hoy en trance de desarrollo» (Holt y Turner, 1973, p. 15).

Las frustraciones de todo tipo que, en la actualidad, están sufriendo los países que en mayor o menor grado intentaron llevar a la práctica los modelos desarrollítiscos, ha supuesto un cambio y una revisión del paradigma modernizador (M. Dobru, 1990, p. 256) que en adelante será concebido como fundamentalmente «conflictivo» y no, como ingenuamente se suponía, a partir de condicionamientos funcionalistas, como una serie ordenada de etapas de desarrollo que en virtud de la lógica progresista inherente a este enfoque había de conducir a la identificación con los modelos históricos propuestos.

Treinta años después de estos plantamientos, es ya posible volver sobre los mismos para intentar alguna suerte de balance, siquiera sea provisional, de lo conseguido y, más aún, del estado actual de la cuestión, para lo cual puede ser útil traer a colación el clásico modelo de las crisis o umbrales de desarrollo popularizada por Almond y Powell y los componentes del «Comittee an comparative politics» del «Social Science Research Council» (Pasquino, 1974, p. 49).

De acuerdo con esta orientación era posible identificar cinco tipos de umbrales que habrían de ser atravesados con un mínimo porcentaje de éxito por los nuevos 
Estados surgidos de los movimientos descolonizadores a fin de lograr la consolidación de sus respectivos procesos de instauración.

De forma esquemática estos umbrales serían:

1. 1. Umbral de legitimidad

1. 2. Umbral de participación política

1.3. Umbral de penetración

1. 4. Umbral de identidad

1. 5. Umbral de distribución.

Siguiendo este modelo parece posible intentar explicar la crisis que actualmente afecta al Estado-Nación en los países musulmanes del Norte de Africa con especial énfasis en lo que ocurre a nuestros vecinos del Maghreb.

\section{1. Umbral de legitimidad}

Desde un punto de vista teórico este tipo de secuencia o de meta puede enmarcarse en el campo de la «cultura política» y concierne directamente a las relaciones entre gobernante y gobernados, así como a las divergencias que puedan aparecer en el seno de una sociedad dada, en torno a la narturaleza más apropiada de la autoridad.

Si desde el planteamiento normativo trasladamos esta noción a la realidad sociopolítica podemos observar que en los países del Norte de Africa, el Estado que se instaura en torno a la década de los sesenta, nace entre grandes entusiasmos colectivos y magníficas esperanzas, pero carece, en cierta medida, salvo en el caso marroquí, de un apoyo que podríamos llamar «óntico» o sustancial, por la ausencia en el vértice del sistema de un órgano que pudiera ser considerado tradicionalmente como legítimo y que, a su vez, infunda algunas dosis de legitimidad al sistema político (Lipset, Some social requisits of democracy, citado por Pasquino, 1974, p. $56)$.

Es muy significativo, en este sentido, que las Constituciones de los nuevos Estados islámicos, hagan siempre referencia a una suerte de comunida transnacional (la UMMA), políticamente vigente, que sirve como de asiento y base a la emergentes legitimidades y que suaviza un tanto lo que la idea del Estado tiene de «préstamo cultural» (Emilio García Gómez, El arte dormido, ABC 31-V-92) para estas sociedades. Basten como soporte de las ideas anteriores las continuas referencias que los primeros artículos de las Constituciones de los países islámicos suelen hacer a la «gran nación árabe» o al «Maghreb», que además de convertir de facto al Estado en algo transitorio y vicario, ha permitido acuñar la expresión de «nación a dos niveles» como elemento caracterizador del sistema político (Abdel Malek, La pensé politique arabe contemporaine, cit. por Bernabé López García, 1985, p. 23). 
La consecuencia inmediata de esta situación es la constatación de un déficit inicial de legitimidad que, en alguna medida, ha condicionado la salida, en la carrera histórica hacia el desarrollo, de estas sociedades y que se explica, como ya adelantábamos más arriba, por el hecho de que la forma política que en Occidente conocemos como estado Moderno, no se corresponde con las tradiciones históricopolíticas del mundo islámico en el que se establece como institución importada y/ o impuesta en un medio cultural extraño si no hostil.

Problamente no esté de más recordar, al hilo de estas reflexiones, que la ruptura del universo político medieval y su fragmentación están en la matriz histórica de la emergencia del Estado en Occidente y que, en los casi quinientos años transcurridos desde su nacimiento, aquella realidad específicamente europea ha pasado a convertirse en estructura política de aceptación universal. Lo cual no implica que la generalizada implantación de este «invento» europeo tenga que ser acogido por doquier, al menos en términos teóricos, con la misma facilidad que en su ámbito originario.

Acontecimientos tan recientes como la «Guerra del Golfo» y el casi general grito de protesta de las masas musulmanas desde el Indico al Atlántico, permiten suponer que el «casus belli» inicial: «La violación de las fronteras de un Estado soberano», no era percibido con la misma gravedad en la mentalidad occidental que en el corazón del mundo musulmán, precisamente por la falta de arraigo de la dimensión estatal en el alma colectiva islámica.

Sin embargo, dar cuenta de esta contradicción, especialmente sensible para el etnocentrismo occidental, supone volver al estudio, en parte abandonado en algunos sectores de la Ciencia política, de las consecuencias sociales y políticas que toda Religión supone para el ambiente en el que se desenvuelve. En este sendtido una Ciencia política que se limite al puro conocimiento de lo político en sus apectos estricamente técnicos, con olvido de sus aspectos míticos, religiosos o experienciales, corre el riesgo de no poder explicar satisfactoriamente los complejos procesos sociales que nos ha tocado vivir y quizás no pueda ayudar a resolver los graves problemas que, a no dudarlo, se van a presentar — de hecho ya lo están haciendoen la entrada del nuevo milenio.

Desde una perspectiva que intentaremos más amplia, la comprensión de las sociedades islámicas en su vertiente política, tiene que partir de la abslouta indiferenciación existente en las mismas entre las esferas de lo político y de lo religioso. La identidad se da, incluso, en el orden lingüístico en el que, cuando del Islam se trata, no hay equivalente para lo que en Occidente se entiende por la voz «laico» (Lewis, 1990,p. 14). El Islam es, ante todo, «comunidad básica»-UMMA de la raíz UMM: madre, pero comunidad básica de hombres movidos por la misma fe religiosa.

La UMMA es noción central a retener para poder acercarnos a la comprensión de los problemas que aquejan al mundo árabe en general y al discurso islamista en particular. Esta comunidad de creyentes se articularía en torno a una «ciudad 
musulmana ideal» dotada de un régimen político que ha sido objeto de una literatura considerable: «El Califato». En la realidad histórica este sistema no estuvo mucho tiempo vigente, pero en la memoria colectiva de los pueblos islámicos representa una mítica «Edad de Oro» del régimen político árabe que en cada situación de crisis pugna por imponerse y recuperar el protagonismo perdido. Esto se explica porque los países árabes, como señala Flory $(1962$, p. 131), «si bien pertenecen como muchos otros al Tercer Mundo subdesarrollado, en gran proporción, sin embargo, proceden de una muy vieja familia política, que a diferencia de la mayor parte de los países del Africa Negra, tienen una larga experiencia del poder y de la vida internacional». La referencia a esta «comunidad árabe», que como se decía antes se encuentra en la inmensa mayoría de las Constituciones de los países islámicos, es expresión del sentimiento existente en el interior de los modernos Estados musulmanes de formar parte de una misma familia política, lo que por pura lógica, da lugar a una percepción de la soberanía estatal distinta de la genuinamente occidental y, por tanto, ya no tan acorde con el bodiniano concepto de la «suma in cives potestas», sino más en consonancia con una noción de soberanía sometida a la condición resolutoria de que no se cumpla la esperada unidad en el seno de la común nación árabe.

En este sentido, el hecho de que la «Revolución libia» de 1969, una vez triunfante, no se dotara de nuevas instituciones, excepto el Consejo de la Revolución, es reveladora de esta muy peculiar manera de pensar que suponía que la construcción de futuras estructuras unitarias habrían de proteger a la «Revolución libia» de caer en los «particularismos» del régimen anterior (López García, 1988, p. 319).

En este punto, se podría insinuar la existencia de un cierto paralelismo entre la noción islámica de un Estado sometido, en cierta medida, a la condición resolutoria de que no sea construida «la ciudad ideal musulmana» y algunas de las estructuras constitucionales, recientemente desaparecidas de los, en otro tiempo, llamados Estados de «socialismo real» que también, al menos teóricamente, debían permanecer hasta la necesaria e inedefectible formación o advenimiento de la «sociedad sin clases». En ambos casos y aquí probablemente acabe el paralelismo, se produce una apelación a una realidad transhistóricia, anclada en el futuro, en el caso de los denominados en otro timpo, Estados «comunistas» y vuelta hacia un mítico «pasado feliz» en el caso del mundo islámico. En este último caso es posible hablar de un mundo común a partir de la historia, la lengua o la religión configuradores de una experiencia previa de nación unida, que contrariamente a lo ocurrido, por ejemplo, en la América hispana, constituye una referencia obligada a la reflexión árabe en su largo proceso de decadencia posterior. Hermassi señala que la existencia de la utopía árabe supone una «concepción alternativa» en el orden político que, especialmente en momentos de crisis como la presente, contribuyen a privar al estado de amplios soportes de lealtad, de tal manera que no le quedaría sino la fuerza para imponerse, lo que, por otra parte, ayudaría a explicar, en parte, las posturas autoritarias 
adoptadas en general por los Estados modernizadores. De manera gráfica se describe esta situación por Laroui (cit. por Hermassi. Le nouvel Etat et les resistences de la societé civil. A.A. du Nord, 1983, p. 89) en los siguientes términos: «El Estado equipa, enseña, emplea y organiza... pero en realidad estas realizaciones no le procuran ninguna lealtad, no crean ningún consenso en torno a él, tanto más cuanto que su propaganda no cesa de repetir que él no es más que una etapa en la vía hacia el gran Estado Arabe». En definitiva, se podría afirmar que entre la funciones que el Estado ejerce en estas sociedades y la ideología que vehicula y difunde, existe una contradicción que empujaría a sus súbditos a no tomarle verdaderamente en serio. $\mathrm{Si}$ bien las anteriores afirmaciones tendrían que matizarse con la distinción de diferentes especies de sensibilidad frente al fenómeno estatal entre las sociedades magrebíes, que no serían tan negativas, y las del medio Oriente que consideran al Estado como una creación artificial del colonialismo.

Lo que no se puede olvidar es el hecho, válido para todo el mundo musulmán, de que las ambiciosas expectativas de la modernización habían colocado al EstadoNación en el centro de todo el proyecto, lo que repercute ahora contra el mismo al irrumpir en la arena política los marginados y los excluidos del crecimiento. Ante la constatación del fracaso en «dar alcance a Occidente» no es raro encontrar algún autor como Saadi (citado por M. Masmoudi, en Les arabes dans le tempete, 1970, A.A.N., 1983, p. 421) que considera bloqueados a los países del Maghreb y del Machreck, y se pregunta si estos países que han tomado prestado de Europa el Estado-Nación, llegarán a inventar modos de gestión y de organización comunitarios propios ya que: «Los Estados-Nación y los jefes que los encarnan, no sólo han dividido en trozos a una comunidad heredada, sino que también han mantenido a nuestros pueblos separados por fronteras artificiales y han llevado el troceamiento al interior de cada uno de nosotros».

Frente a las posturas anteriores, muy radicales, no faltan quienes ven en este cúmulo de declaraciones, conflictos, resistencias y cuestionamientos, la expresión de las aspiraciones insatisfechas de una sociedad civil en proceso de formación, el despego y la desafección frente a las políticas llevadas a cabo en estos años y muy esepcialmente la esperanza en la emergencia de un nuevo proyecto que arrincone y enderece los desastres provocados por el Estado modernizador. Como afirma M. Flory (1970, p. 158): «No es posible el retorno a un «Dar al Islam» único, en referencia al gran período califal, ya que sería olvidar la llegada a la escena mundial de los Estados soberanos y del nacionalismo que se ha impuesto por doquier a partir del siglo XIX. En adelante el gobierno de los pueblos pasa por el Estado, y la sociedad inetrnacional se concibe como una sociedad de Estados. El retorno a la «ciudad musulmana» no sería entonces en ese contexto más que un sueño anacrónico».

Como hipóetsis intermedia en la década pasada se abrió paso la argumentación sostenida por Santucci (1983, p. 411) de que el mito del Maghreb se esté utilizando como una ideología alternativa a la crisis actual de los Estados en los países norteafricanos. 
En suma, y como con reiteración venimos sosteniendo, la crisis económica y social de estos países se ha transformado en una crisis de Estado caracterizada por un déficit estructural de legitimización, agravada, además, por el fuerte atractivo de un islamismo militante que en principio, rechazaría los intentos de las élites dirigentes de construir campos alternativos de referencia comola U.M.A. (Unión del Maghreb Arabe). Es revelador en este sentido que Abas Madani, dirigente del FIS argelino (hoy puesto fuera de la ley), preguntado en una ocasión por esta entidad, contestara: «LLaU.M.A.?. No, lo que importa es la UMMA» (Del Pino, 1992,p. 16). La cumbre de la UMA celebrada en noviembre de 1992 en Rabat parece que intenta avanzar por este camino al tiempo que condena «por opuesto a la tradición islámica de tolerancia» al movimiento fundamentalista.

\subsection{El umbral participativo}

Siguiendo con el modelo clásico propuesto por Almond y Powell, por umbral participativo o crisis de participación hay que entender el grado de inserción de los individuos y, también de los grupos sociales en el proceso político. Ello implica tener en cuenta el «conjunto de procesos por medio de los cuales los ciudadanos influyen o controlan a quienes toman las decisiones más importantes que les afectan» (Verba, 1967, citado por Pasquino. Modernización política, 1974, p. 67). Queda claro, por tanto, que si bien este proceso ha sido identificado tradicionalmente con el conjunto de luchas políticas que especialmente en Occidente han tendido a la ampliación del derecho activo de sufragio, no es menos cierto que esta noción puede extenderse también al estudio de los conflictos que tienen o han tenido por objeto el acceso de los distnitos grupos sociales a esferas de decisión más reales.

Ante la situación de hecho que, en la actualidad, existe en los países islámicos, con unas élites fuertemente atrincheradas en los reductos del poder, la pregunta inevitable tiende a averiguar la causa por la que la democracia política se muestra tan difícil de instaurar en estos sistemas sociales. La respuesta más inmediata tiende a relacionar esta situación, como ha hecho Nair (1990, p. 233) con la persistencia de Estados autoritarios o fuertes opuestos hasta épocas muy recientes, y hoy algunos, como Argelia, en clara situación involutiva, a cualquier pluralismo participativo. La razón última no sería otra que la subordinación de las demandas participativas al necesario desarrollo económico. El mecanicismo de este modelo se revela aquí en toda su dimensión por cuanto que en estas sociedades los intentos de transformación social perseguidos, por lo demás con los magros resultdos que saltan a la vista, no se han realizado siguiendo los procesos de desarrollo histórico y político de las sociedades occidentales, sino más bien mediante la utilización del poder político en su versión centralizda y autoritaria- como palanca eficiente del desarrollo por parte de las «élites modernizadoras». Ello ha conllevado situaciones de 
desmovilización o de escasa participación política en grandes núcleos de población que han visto así frustradas sus expectativas de integración, con las secuelas negativas del exceso de burocratización y reducción sistemática del espacio público a espacio ocupado por élites.

Podríamos decir que la lógica impulsora del «desarrollo modenizador» podría parangonarse a una suerte de «revolución desde arriba» que habría fracasado en el logro de gran parte de sus objetivos: industrialización eficiente, independencia económica y transformación positiva de las condiciones reales de existencia de amplias capas de población. En resumen, si se quisiera hallar una diferencia sustancial entre los procesos históricos que en la actualidad se están produciendo en el Maghreb y los que han caracterizado la formación de los sistemas sociales y políticos occidentales se podría afirmar que consistiría en la ausencia, prácticamente total, de articulación entre los intentos de transformación económica y la institucionalización de los antagonismos sociales a través de cauces democráticos.

Si analizamos los procesos electorales que, intermitentemente, han tenido lugar en Argelia, Marruecos o Túnez, podemos observar que en ningún caso, salvo en el interrumpido proceso argelino de 1991-91, se puede hablar de una participación popular normal. Así, en Marruecos ya la primitiva ley electoral de 1960 será una norma parcial en beneficio de los candidatos de las zonas montañosas y semidesérticas en detrimento de las zonas urbanas, lo que, no obstante, no impediría la proclamación del Estado de excepción entre 1965 y 1970, los golpes militares frustrados en los años siguientes, o el rechazo de los resultados de los «referenda» posteriores por parte de la oposición.

En Argelia el papel hegemónico que hasta 1991 ha protagonizado el F.L.N. se ha tenido que resolver en una crisis institucional que sólo un verdadero golpe de Estado ha intentado paliar en sus consecuencias. Por último, en Túnez, la prepotencia del partido Socialista desturiano y el fracaso de la oposicción, más como consecuencia del fraude electoral que de una legislación hecha a la medida del partido del poder, van a terminar en el «impasse» actual de carácter autoritario debido a la proposición de las élites dirigentes al empuje relativamente fuerte del islamismo (López García, 1985 , p. 243 y ss).

Si bien los interrogantes que plantean este tipo de cuestiones se han respondido desde el enfoque de la cultura política con la argumentación de que los sistemas democráticos no serían, sin más, traspasables a las culturas específicas y tradicionales del tercer mundo. Sami Nair (1990, p. 243) considera, sin embargo, que la ausencia de mecanismos de institucionalización de conflictos, especialmente de parlamentarización y de competición política, es más bien consecuneica de la especificidad de los «sistemas sociales globales» del tercer mundo que se encuentran interiormente divididos en subsistemas radicalmente antagónicos, lo que en opinión de Nair, haría prácticamente inevitable la emergencia de formas estatales «fuertes» precisamente para hacer posible el mantenimiento de esos sistemas. 
La raiz del problema se encontraría —en la tesis de Nair-en el hecho de que desde su independencia estas nuevas naciones se encontrarían con una economía ya organizada mundialmente y por tanto, en alguna medida, «cerrada», en contraposición al mundo «abierto» en el que se desarrollaron los procesos de modernización de los países occidentales a lo largo de los siglos XVIII y XIX. La consecuencia lógica, de admitirse esta hipótesis, es que el subdesarrollo no sería una etapa más o menos coyuntural para estas sociedades, sino más bien una situación con visos de permanencia, en correspondencia con la rigidez de la organización del sistema económico. La «Centésimus annus» de Juan Pablo II, ha puesto de relieve (Bac. 1991, p. 57) que «el mayor problema de los países más pobres está en conseguir un acceso equitativo al mercado internacional, fundado no sobre el principio unilateral de la explotación de los recursos naturales, sino sobre la valoración de los recursos humanos».

El hecho real es que en la actualidad las sociedades de los países subdesarrollados se encuentran escindidas entre un «subsistema integrado» y otro «marginal»: Al subsistema integrado pertenecerían las viejas aristocracias terratenientes y burguesas, las nuevas capas industriales y financieras, el funcionariado y el proletariado industrial que a pesar de eventuales antagonismos se beneficiarían de los mejores recursos del sistema. Frente a este espacio, el campo de la marginalidad no participante se caracterizaría básicamente por la exclusión estructural de los elementos sociales de las esferas de la producción económica y, por supuesto, de la decisión política. Para estos sectores, muy importantes numéricamente, existe una exclusión más o menos radical, según los casos, pero importante, de las ventajas y beneficios ligados a la institucionalización político-social. En suma, el «ethos» que informaría a estas capas sería una cultura de la «sobrevivencia» sobre la que operaría una racionalidad desprovista ya de cualquier barniz de «tradicionalidad» sino más bien referente a valores impregnados de nuevos componentes comunitarios y religiosos.

En definitiva, como afirma Lamchichi (1990, p. 80), el desarrollo considerable de la marginalidad y la exclusión social de numerosas capas de origen rural, recientemente asentadas en los núcleos urbanos, se encuentra en el origen de la base social del islamismo radical, cuyos militantes son, en parte, jóvenes instruidos en los modernos sistemas escolares y a menudo con formación universitaria lo que, unido a los problemas derivados de la explosión demográfica en estas sociedades, el 60\% de la población tiene menos de 25 años en Argelia, explicaría la virulencia de la contestación social y la amplitud y extensión del fracaso de la participación como umbral necesitado de superación. 


\section{3. El umbral de penetración e integración}

Este tipo de procesos se refiere fundamentalmente al conjunto de medios que históricamente han solido utilizar los Estados para hacer valer su autoridad penetrando en los diferentes sectores sociales con el fin de lograr una trabazón orgánica entre este poder contral y la amplia malla de las autoridades locales (Pasquino, 1974, p. $50)$.

El concepto de penetración no sólo puede ser entendido en sentido espacial o territorial sino también vertical, es decir, tomando a la sociedad en su conjunto como objeto a integrar. Tradicionalmente, los estímulos para esta penetración estatal han solido ser de tipo económico, político o militar y normalmente han adoptado tres tipos de soluciones: la conquista, la fusión y la irradiación, dependiendo en cada caso de concretas circunstancias históricas o tópicas.

Es evidente, volviendo a nuestro tema, la importancia que la penetración por irradicación ha tenido en los nuevos Estados surgidos de la descolonización como los norteafricanos, cuyo objetivo no podía ser sino la destrucción o, al menos, la atenuación de los vínculos sociales de carácter tradicional, como las redes clientelares, que evidentemente, consituían a priori un impedimento, no sólo para la transferencia de obediencia a las autoridades centrales sino también para la adquisición de nuevas formas de comportamiento.

En este sentido, el fracaso en la penetración de los nuevos Estados en las sociedades islámicas, ha permitido el mantenimiento y aún la creación de relaciones de patronazgo, lo que ha podido ser fomentado como ya señalara Gellner (1977, p. 13), por los defectos en el funcionamiento del mercado o la ineficacia de una burocracia corrupta. Podemos por tanto, señalar que el umbral de penetración no estará suficientemente traspasado, cuando, por encima de afirmaciones retóricas, los vínculos de carácter familiaristas se superponen a las que en teoría debieran ser relaciones impersonales, ajustadas, en la medida de lo posible, al principcio general de igualdad ante la ley.

De esta manera, un Estado con escaso poder integrativo, pero no tan débil como para tolerar el feudalismo abierto y reconocido puede, por este mismo motivo, estimular indirectamente la aparición del reforzamiento de situaciones de aquél carácter en las zonas más apartadas de su influencia. Por otro lado, cuando las sociedades tienen un alto componente de elitismo, como sucede con las del otro lado del Estrecho en donde priman componentes de tipo gratificante y adscriptivo, el clientelismo tiende a volverse endémico, constituyendo así como una red o una malla que dificulta la acción del Estado. Frente a esta interpretación, algún autor como Silverman (1986, p. 18) ha llegado a afirmar que el mediador, cacique o patrono, representa una forma general de relación entre la comunidad y el Estado en la fase inicial de los Estados-Nación que no entorpece la expansión estatal, ya que, afirma Gellner (opus cit., p. 125), la burocratización paulatina de las relaciones 
patrono-cliente contribuye a reducir los sentimientos de dependencia personal así como el contenido moral que antes caracterizaba estas relaciones. Desde este enfoque la presencia de partidos políticos permite una transformación de estas relaciones cunado no consigue la completa sustitución de las redes mediadoras por las organizaciones dependientes de aquellos.

Como ejemplo pionero suele citarse el caso de Turquía a principios del siglo XX en que la presencia del Estado en sus provincias más alejadas se hizo sentir en forma de impuestos, conscripción militar, tribunales y exigencia de títulos para la tenencia de tierras. Con el fin de solventar los problemas derivados de esta nueva presencia, los campesinos buscaban, en principio, el apoyo de los notables. Sin embargo, en la actualidad (Gellner, 1986, p. 141), la influencia política de los notables ya no se deriva, como antaño, del control de los recursos de influencia tradicional sino de los cargos que ostentan como funcionaros del partido. A esta situación coadyuva, evidentemente, la valoración creciente que el campesinado otorga a sus votos como poderoso factor de negociacación en sus tratos con los funcioonarios de los partidos interesados.

La situación descrita tiene un correlato evidente en Líbano donde a principios de los setenta, las relaciones de patronazgo eran importantes en la zona de Akkar, al Norte, que precisamente era una de las últimas incorporadas al Estado libanés. Samir Jalaf (1986, p. 200) afirma que, en esa época «Al igual que el confesionalismo, el patronazgo había quedado institucionalizado en el cuerpo político del Líbano como un mecanismo adaptativo de modernización».

Dentro de este mismo esquema explicativo Clement Henry Moore (1986, p. 228) justifica la pervivencia de las redes clientelares en los países del tercer mundo como una mera consecuencia del cambio en la entidad de las relaciones de intercambio en la medida en que la modernización permite a los patronos recurrir a recursos de segundo orden como son los cargos burocráticos o la influencia política, dejando de lado los recursos tradicionales como la riqueza o la sabiduría.

En Argelia, el Estado modernizador también parece enfrentarse a este tipo de resistencias en sus intentos de penetración social. La explicación puede encontarse en el hecho de que el clientelismo actúa como un mecanismo promotor de la integración de las capas de población marginal y periférica en el tejido de la vida nacional. Sería justamente la situación de vacío ideológico y de aislamiento del resto de la población en que se sitúan los cuadros tecnocráticos lo que explicaría la pujanza del clientelismo en Agrelia (Bruno Etienne, 1986, p. 274) en cuyas redes de solidaridad ha encontrado adecuado caldo de cultivo el movimiento islamista.

Por último, en Marruecos, la atipicidad de su régimen y el difícil equilibrio que se intenta entre unos estratos sociales dominados por la tradición y un sector elitista modernizante, permite sospechar que, como afirman algunos autores (Kenneth Brown 1986, p. 318), las limitaciones a la libertad política existentes en Marruecos, si bien hacen difícil un juicio exacto sobre la importancia del patronazgo en los 
momentos actuales, han debido reforzar los vínculos de tipo familiarista especialmente entre las élites. Confirmación de lo dicho son las declaraciones del gobierno marroquí tras el Referendum de 1992, caracterizando al Estado marroquí como una «gran familia».

En síntesis, podemos concluir afirmando que el «mundo de solidaridades primarias» existente, en estos países, en muchos casos hoy en torno a la Mezquita, se ha revelado como un serio obstáculo al proceso de instalación paulatina de las instituciones del Estado en su intento de modernización de estas sociedades a través de miméticos procesos de imitación de los «ismos occidentales» (Udo Styeinbach, ABC, Análisis, 23-II-92).

\subsection{El umbral de identificación}

El espectro de problemas sociales que abarca esta expresión es de tal amplitud que tanto puede referirse a la emergencia de nacionalismos como deseos independentistas, dentro de un enfoque «culturalista» de la política, como a los fenómenos de desarraigo o anomia colectiva que suelen producirse en los movimientos migratorios interiores o exteriores. En todo caso, como ya señalara Dobry (1990, p. 256), este tipo de planteamientos reenvía a la base subjetiva de pertenencia a la comunidad o, como afirma Pasquino (1974, p. 54), atiende a la actitud de la población respecto del sistema político.

Lo que es evidente es que el fenómeno de la identidad se ha instalado como problema de primera magnitud en la agenda de los noventa como consecuencia de la interrelación de dos tendencias que caracterizan al mundo actual (Tortosa, 1992, p. 2): por una parte, es patente la existencia de una creciente mundialización del sistema económcio, y por otra, hay una correlativa tendencia a desarrollar una exaltación de los localismos de tipo cultural. Para el autor citado, «tanto la globalización como la localización tienen efectos sobre el problema de la identidad que en estos momentos es experimentado como una auténtica necesidad básica que exige, en gran parte del planeta, una auténtica satisfacción».

Desde esta perspectiva, es evidente que las sociedades islámicas en general y las magrebíes en particular están viviendo en estos momentos una acentuada crisis de identidad que, básicamente, proviene del choque con los modelos de vida del mundo occidental, a lo que, evidentemente, coadyuva el desarraigo individual que en los últimos años se ha producido en las masas deficientemente urbanizadas concentradas en torno a las aglomeraciones urbanas.

En la medida en que el Estado modernizador no ha logrado superar en el Maghreb esta crisis de identidad haciendo posible que los individuos se sientan parte del sistema político, se ha producido en las masas musulmanas un retorno a las raíces de su identidad básica que es, no lo olvidemos, la «comunidad credencial»: la 
UMMA. Como afirma Lewis (1990, p. 116), el Islam es para el creyente mucho más que su país, su origen étnico o su lengua. En este sentido en 1917, el Gran Visir del Imperio Otomano declaraba que: «la patria de un musulmán es cualquier lugar en el que permanece la Sharïa» (Lewis, 1990, p. 144). La quiebra del actual modelo de Estado es tanto más patente cuanto que si bien en los catorce siglos de historia islámica pocos gobiernos se habían adherido estrictamente a la «Sharïa», ello habría ocurrido por error o elusión pero no por enfrentamiento directo. Sin embargo, en los Estados surgidos de la descolonización, no era extraño que, en áreas importantes para la mentalidad islámica, se derogara esta ley básica sustituyéndola por sistemas normativos extraños al mundo musulmán y por tanto, de origen «no divino», lo que suponía el intento de destrucción de sus creencias básicas.

En defintiva, como afirma Quiñonero (Análisis de ABC, 1992, 23-2), las modernas sociedades magrebíes se encontraban cogidas en la trampa de creer que su proceso de modernización debía ser el resultado de un mimetismo cuasi mecánico de los logros occidentales, pero este proceso de imitación y con él el modelo estatal que lo auspiciaba ha quedado detrozado tras las sucesivas contiendas bélicas que se han sucedido entre 1967 y 1991. Muchas voces han señalado desde entonces que «el camino recto no estaba en la separación de política y religión sino en la unión indisoluble de ambas, no en la importación de ideologías occidentales, como paradigmáticamente habría hecho de manera especial Argelia o Túnez, sino en la ideologización del Islam. No en la secularización sino en el Islamismo» (Udo Steinibach, Análisis de ABC, 1992, 23-II). Desde esta perspectiva se argumentaría que la verdadera exigencia de modernidad del Islam consistiría en crear un orden político, social y d evalores que permita vivir al musulmán en una armónica compatibilidad entre su sistema básico de referencia y lo actual de la ciencia y de la técnica.

Es evidente que este problema, no resuelto, de la identidad en el mundo magrebí se ha visto en nuestros días agravado por el descontrolado movimiento de urbanización cumplido en estos pasados años que ha dado lugar a la transformación de las ciudades magrebíes en el lugar donde, como afirma Lamchichi (1989, p. 44), se condensan las contradicciones de la sociedad y donde cristalizan los conflictos y tensiones inherentes al desarrollo, señalándose de manera muy nítida la marginalización de amplias capas de población. En suma, las «revueltas del hambre» de Argelia, Marruecos o Túnez de finales de la década de los ochenta, no son más que el detonante que delata el fracaso del modelo magrebí hacia el desarrollo. Este fracaso se produce por la confluencia de tres factores que actúan sinérgicamente:

1) El rechazo masivo de amplias capas de población fuera de las esferas productivas.

2) La ausencia de instituciones políticas de integración y de expresión democrátcia de los conflictos y 
3) El sentimiento de pérdida de la identidad cultural y/o religiosa, consecuencia de la influencia de las mass media y de los esquemas de vida occidental.

Es en este marco en el que los movimientos islamistas han resucitado, con mayor o menor virulencia según el país, el proyecto utópico de refundación de la sociedad musulmana básica; así como la reconversión de todos los valores sociales en los principios de la UMMA musulmana. Su proyecto consistiría (Lamchichi, 1989, p. 89) en un contramodelo de modernización mediante la denuncia de los efectos perversos de ésta: aislamiento social, individualismo exacerbado, pasividad política, inflación burocrátcia, masificación y marginalidad. Para este autor, los sistemas políticos del Maghreb viven en estos momentos una situación ambivalente que hace coexistir, muy difícilmente, una racionalidad estatal importada y un fondo cultural propio enraizado en la dimensión religiosa que halla su expresión, en ocasiones próxima al paroxismo, en las grandes ciudades.

Lianz (L'imposible modele urbaine dans le trens monde. Le monde diplomatique. Mai 1988, p. 18 y 19. Cit. por Lamchichi, 1989, p. 91) observa que en la actualidad el $70 \%$ de la población iberoamerciana y el $50 \%$ de la del mundo árabe, vive y sobrevive en la ciudad y explica que: «La crisis de la urbanización es un fenómeno multidimensional resultante de la descomposición de las estructras rurales, de las prácticas estàtales, de la mundialización de las sociedades y de la propia dinámica generada por el proceso urbanizador».

Tabla I

\begin{tabular}{|c|l|lc|}
\hline Países & Ciudades principales 1983 & $\begin{array}{l}\text { Tasa de urbanización } \\
\% \text { de pobl. urban. }\end{array}$ \\
\hline & & 1960 & 1980 \\
\hline Argelia & $\begin{array}{l}\text { Argel (280.000), Orán (500.000), } \\
\text { Constantina (430.000 }\end{array}$ & 30 & 33 \\
\hline Marruecos & $\begin{array}{l}\text { Casablanca (1.371.000), Rabat } \\
\text { (436.000), Marraquech (330.000) }\end{array}$ & 29 & 41 \\
\hline Túnez & $\begin{array}{l}\text { Túnez (550.000), S Fax (171.000), } \\
\text { Soussa (70.000) }\end{array}$ & 36 & 52 \\
\hline
\end{tabular}

Fuente: Claude Chaline. Les villes du monde arabe, 1990, p. 18. 
El resultado de las políticas estatales que consideraban a las ciudades como «motores de crecimiento», es que mientras las emergentes clases medias han sido favorecidas con toda clase de privilegios (empleos en empresas estatales, acceso a bienes raíces, estc.), las capas menos afortunadas atraidas por los modos de vida y de consumo urbanos o echados del campo por la crisis de la agricultura tradicional son víctimas de los planes de «ajuste»o «desenganche social» impuestos por el F.M.I., con el riesgo consecuente de desencadenar las ya conocidas «explosiones de la miseria». Claude Chaline (1990, p. 16 y 18) afirma que sobre un total de 200 millones de habitantes para 1986, el mundo árabe tenía una tasa de urbanización del $50 \%$, con una tendencia en progresivo aumento desde el $25 \%$ de 1950 , hasta el $60 \%$ esperado para finales de siglo.

Tabla II

\begin{tabular}{|llll|}
\hline A. del Norte & Población & $\%$ Pob. urbana & Crecim. Pob. urbana \\
\hline Argelia & 22,4 mill. & $43 \%$ & $3,7 \%$ \\
Egipto (1986) & $50,4 \ll$ & $50,4 \%$ & $3,4 \%$ \\
Libia & $3,9 \ll$ & $78 \%$ & $6,7 \%$ \\
Maroc & $22,5 \ll$ & $44 \%$ & $4,2 \%$ \\
Mauritania & $1,8 \ll$ & $31 \%$ & $3,4 \%$ \\
Sudán & $22,6 \ll$ & $21 \%$ & $4,8 \%$ \\
Túnez & $7,3 "$ & $56 \%$ & $3,7 \%$ \\
\hline
\end{tabular}

Fuente: Claude Chaline. Les villes du monde Arabe, 1990.

Paradójicamente, este amplio movimiento urbanizador ha tenido el efecto de romper la tradición «insurreccional» del campesinado, sentida en amplios espacios del Maghreb, especialmente en la época precolonial (A. Zghal, 1975, p. 296). El mundo rural magrebí da en estos momentos la impresion de encontrarse en calma, al contrario de lo que ocurre en las ciudades, lo que, en principio, puede explicarse por las consecuencias que la incipiente mecanización rural han producido en la estabilidad y seguridad del empleo, así como por el hecho de que aproximadamente un $20 \%$ de la población activa de los países del Maghreb vive en los países del Mercado Común.

Como resumen podemos concluir afirmando que la crisis que en la conciencia colectiva musulmana ha provocado el intento de importar los modelos occidentales, explica tanto las situaciones de anomia y desilusión que en la actualidad viven como el vigor de los movimientos islamistas que han convertido a las Mezquitas en 
«lugares de refugio» aisladas del resto de la ciudad en la medida en que el musulmán reencuentra en ella algo de su perdida identidad (Lamchichi, 9. 94).

\section{5. El umbral de distribución}

El último de los estadios que integran el recientemente redefinido paradigma modernizador es el constituido por el umbral de distribución que, en síntesis, vendría asociado al intento, que el Estado habría de cumplir, de lograr un reparto equitativo tanto de bienes y servicios materiales como de valores simbólicos. Es evidente que, en estos países, tal cometido viene, de suyo, encomentado a las instancias y agencias estatales y supone, como argumenta Pasquino (1974,p. 72), la consiguiente elección en la utilización de los poderes del Estado, así como la imposición de regulaciones y una optimización en la organización de los recursos humanos. Estas exigencias distributivas adquieren especial relevancia cuando tanto el umbral de legitimidad como el de participación, no han sido resueltos en estas sociedades de modo satisfactorio, lo cual, a la vista de los menguados resultados obtenidos, igualmente, en este capítulo, como veremos más adelante, ha devenido en importante descrédito para todo el proceso de modernización.

Sami Nair (1990, p. 233) aplica sin paliativos la palabra «fracaso» a la incapacidad de las nuevas naciones para resolver, de manera adecuada, los problemas de tipo económico que constituian algunas de las motivaciones justificadoras de su nacimiento. La explicación de este fracaso, al que ya nos hemos referido más arriba, se encontraría en el hecho de que «toda formación nacional nueva se hallaría enfrentada a la existencia de una economía ya organizada mundialmente que le asignaría una plaza y unas funciones relativamente predeterminadas».

Es evidente, a mi juicio, la insuficiencia de esta interpretación, que aunque evidentemente pueda tener elementos dignos de ser tenidos en cuenta, no puede agotar toda la complejidad de las circunstancias sociales y económicas que han concurrido en la incapacidad de estos Estados para hacer frente a sus metas de cara al desarrollo. Estas insuficiencias quedan patentes cuando se observa que no todos los Estados surgidos en el ámbito histórico tutelado teóricamente por las teorías de la modernización han sufrido la misma suerte. Este es el caso de los famosos NIC del Pacífico (Taiwan, Corea del Sur, etc.) que enfrentados a problemas parecidos desde su irrupción en el mundo económico, han podido superar la cerrazón que con carácter absoluto quisiera denunciar Nair.

Probablemente son estos los supuestos aludidos en un reciente documento social de la Iglesia Católica cuando en él se afirma que: «La historia reciente ha puesto de manifiesto que los países que se han marginado han experimentado estancamiento y retroceso; en cambio, han experimentado un desarrollo, los países que han logrado introducirse en la interrelacion general de las actividades económicas a nivel internacional» (Centesimus Annus, 1991, p. 57). 
En todo caso, a la altura de los años noventa es ya posible trazar los rasgos más salientes que en el ámbito socio-económico caracterizan a las sociedades magrebíes:

a) Explosión demográfica espectacular relativamente reciente, aunque con tendencias decrecientes (Lucas Marín, 1992, p. 154).

b) Crisis socio-económica profundamente estructural cuya aceleración supone en estos países terribles problemas de empleo, alimentación y educación.

c) Mantenimiento en la conciencia popular de la ideología del desarrollo que, en la medida en que es defraudada, contribuye, por ejemplo, a alimentar la agitación islamista.

Junto a estos factores, las políticas distributivas se encuentran también en gran medida afectadas por los problemas derivados de la devolución de la «deuda externa» que en un componente importante afecta a los países del Maghreb. Siguiendo a Aksbi (1984, p. 544), podemos exponer las fases del proceso que ha llevado a esta situación:

Primera. Excesivo endeudamiento exterior para financiar los planes de desarrollo.

Segunda. Elevaciones del dólar y de los tipos de interés que hacen imposible la devolución de la deuda, a lo que se acompaña una baja en los precios de las materias primas exportables.

Tercera. Cese en los pagos.

Cuarta. Reescalonamiento de la deuda, con la puesta en marcha de programas de ajuste estructural promovidas por el F.M.I.

Quinta. Deflación y subida de precios.

Sexta. Escasez o carestía en productos alimenticios de primera necesidad. Explosiones populares $\mathrm{y}$ «Revueltas del hambre».

Tomando como marco de referencia concreto la crisis marroquí, podemos afirmar con N. Aksbi cuya exposición seguiremos, que la situación actual es en gran parte consecuencia del fracaso de un «modelo de desarrollo» fuertemente inspirado por los organismos internacionales que, paradójicamente, son hoy los que critican sus resultados. Resultados que no sólo han tenido unas deplorables consecuencias socio-económicas sino que también han afectado a la fundamentación de la legitimación estatal en la medida en que aunque los planes de desarrollo no fueron concebidos para la administración estatal desde el principio, sin embargo ha sido el propio Estado marroquí quien se ha erigido en promotor del mismo.

En sus orígenes más inmediatos, la génesis del modelo agro-exportador marroquí se remonta al período 1964-65, que se caracteriza precisamente por contener la primera crisis financiera conocida por este país desde su independencia. Siempre siguiendo al autor citado más arriba, la petición de ayuda, por vez primera, al F.M.I. y al B.I.R.D., supuso la acogida de expertos de estos organismos con la misión de 
efectuar con carácter general un diagnóstico de la economía marroquí, así como la formulación de un conjunto de recomendaciones para el corto, medio y largo plazo. Como consecunecia, y a la vez que un «Plan de estabilización» se puso en marcha, una misión del B.I.R.D. redactó un informe en el que se contenían los elementos básicos de la estrategia de desarrollo según la directrices de esta instancia internacional. Las prioridades de estos planes se referían a la agricultura seguidos de: turismo, infraestructura económica y formación de cuadros.

De esta manera, de alguna forma vino a decretarse que la vocación del país sería la agricultura y más concretamente una agricultura de exportación de acuerdo con los doctrinarios de la división internacional del trabajo. Se suponía que los cultivos con alto valor de exportación permitirían proveer y pagar las compras necesarias para cubrir las necesidades cerealísticas, base hasta este momento de la agricultura marroquí. Además, la exportación de los productos elegidos debería procurar las divisas necesarias para equilibrar la balanza de pagos y para reembolsar la deuda exterior que se preveía contratar cada vez más masivamente para financiar las inversiones hidroagrícolas. Como efecto indirecto de este plan se preveía la creación de una «clase media» que sirviera de amortiguador social debido a la existencia de una minoría fuertemente enriquecida frente a una aplastante mayoría campesina que manifiestamente no interesa al modelo más que como reserva de mano de obra.

El proyecto agrario gestionado fundamentalmente por el Estado se articulaba en torno a una «política de pantanos», de la misma manera que en Argelia se diseñaron los proyectos de desarrollo en torno a las industrias insdustrializantes. El objetivo simbólico se cifraba en la irrigación de un millón de hectáreras en el horizonte del año 2000, para lo que a partir de 1965 se destina a los gastos derivados de los proyectos de irrigación entre $1 / 4$ y $1 / 3$ de las inversiones públicas y de $1 / 2$ a $2 / 3$ de las inversiones destinadas a la agricultura.

Las consecuencias sociales y, en parte, políticas que han resultado de la aplicación de este modelo podemos, a la vista del tiempo transcurrido, concretarlas de la siguiente manera:

1) Fuerte desproporción entre la superficie regada (aproximadamente $300.000 \mathrm{Ha}$.) y la superficie abandonada a sus propias fuerzas (9.000.000 de Ha.), que a su vez contiene a las $4 / 5$ de la población agraria. A estas circunstancias hay que añadir el fuerte proceso de concentración en favor de los grandes propietarios y la alta mecanizción sobre el total nacional en esta zona que acumula el $44 \%$ del parque nacional de tractores.

2) Existencia de grandes exenciones fiscales en favor de una minoría de terratenientes que de esta manera obtienen fuertes beneficios netos $\sin$ la correspondiente devolución al Estado de parte de sus inversiones.

3) Fuerte disminución de la producción de productos básicos como consecuencia de las políticas de intervención estatal: cereales, leche o girasol con la consiguiente necesidad de tener que acudir a las importaciones de choque. Con ello 
se consuma un divorcio entre las estructuras productivas y el modelo interno de consumo.

4) Discriminación en favor de la agricultura «moderna» del $80 \%$ del crédito total, mientras que a la agricultura «tradicional» se destinan créditos de mera subsistencia.

5) Financiación exclusivamente exterior partiendo del dato, no demostrado, de la ausencia de capital propio. La consecuencia inmediata fue un extraordinario aumento de la deuda pública exterior.

En resumen, los efectos que se han producido en la economía y en la sociedad marroquí podrían ser sintetizados de la siguiente manera:

a) Dependencia alimentaria del exterior como consecuencia de la ruptura del modelo tradicional de producción-consumo. Así, mientras en los años cincuenta eran los cereales los que constituían el primer producto exportado, en los setenta ya son los agrios y las frutas tempranas las que han sustituido a los cereales. Por el contrario, a partir de los años setenta, los cereales, los azúcares y los aceites representan ya las 3/4 de las importaciones alimentarias del país. El resultado es un aumento en la situación de dependencia al ser susceptibles estos productos de convertirse en «armas alimentarias».

b) Agravamiento de las desigualdades territoriales y sociales. La concentración de los esfuerzos del Estado marroquí sobre una décima parte de las tierras cultivables, ha producido entre la población rural una fuerte situación de desigualdad. En definitiva, los proyectos financiados por el B.I.R.D. no han afectado más que a 1'3\% de la población rural - unas 140.000 personas-y en contrapartida, según Aksbi, se han generado más de un millón de pobres absolutos entre 19601967, lo que suponía en la época un 45\% de la población rural.

En suma, el modelo agro-explotador no ha obtenido los fines pretendidos: ni autosuficiencia alimentaria, ni excedentes comerciales, ni ingresos fiscales o financieros, ni elevación en el nivel de vida de la gran mayoría del campesinado. Tampoco los intereses modernizadores han triunfado en Argelia con más de 25.000 millones de dólares de deuda externa y unos dos millones de parados, y en términos relativos, algo parecido ocurre en Túnez.

Es evidente que la atenta lectura de estas situaciones permiten suponer que el umbral de distribución no ha podido ser traspasado con éxito por estos países, con las carencias políticas que están a la vista y de las que no es la de menor porte la contestación islamista. 


\section{LA RESPUESTA ISLÁMICA}

El fracaso del Estado modernizador en atravesar con éxito los umbrales que hemos venido destacando como esenciales para la conclusión de su proceso de instauración, ha traido en la segunda mitad del siglo XX una gran desilusión a los países islámicos. Como señala Lewis (1990, p. 190): «Las panaceas ofrecidas por distintos buhoneros no han curado las enfermedades de los pueblos islámicos. El gobierno constitucional no ha traído la salud, la riqueza o el poder. Los instrumentos occidentales no han funcionado demasiado bien y cada vez más los musulmanes han empezado a buscar en su propio pasado un diagnóstico para sus males actuales y una receta para su bienestar futuro. La Revolución Iraní ha mostrado un camino nuevo que muchos musulmanes quieren seguir, aunque este lenguaje nuevo de los movimientos islámicos deba mucho al resto del mundo tanto como al Islam clásico y profético».

Analizando las corrientes fundamentales, señala Halliday (CIDOB, 1989) que la preocupación central de los movimientos islámicos es el Estado. Cómo resistirse a lo que se considera un Estado ajeno y opresor, el Estado modernizador, y sustituirlo por un Estado Islámico como parte de la unidad más general que es la UMMA, como único cuadro donde se podría elaborar una conciencia colectiva, que no se definiría ya por el «ius sanguinis» o el «ius locis» sino por el «ius religionis». Manifestaciones actuales de la pervivencia de la comunidad religiosa son, por ejemplo, las prohibiciones, contenidas en muchas Constituciones islámicas, de que personas no musulmanas puedan acceder a la Jefatura del Estado o la tendencia a la concentración del poder, junto a la falta de expansión de los mecanismos representativos de la democracia. Esto es así porque en la ciudad musulmana tradicional, el poder no viene de abajo hacia arriba sino mediante una cascada de delegaciones. En última instancia, los jefes políticos no son representantes del Pueblo sino de Dios. Por último, es la comunidad más que el individuo el que vota, de ahí la proclividad de las sociedades musulmanas hacia el partido Unico y la consideración de que los elegidos no están en relación de dependencia con los electos, sino con la «comunidad» que se trata de realizar. Son más bien «Asambleas Consultivas», reflejo de la «Comunidad coherente» que en su casi unanimidad, va a confiar los poderes al Lugarteniente de Dios (Flory, 1979, p. 135 y 49).

El fundamento de esta concepción no es difícil hallarlo en la unión entre el mundo temporal y el religioso, entre lo sagrado y lo profano que provocan una especia de inserción del musulmán en esta sociedad. Como ya destacábamos en otro lugar de este trabajo, el laicisimo a la manera europea no tiene sitio o si lo tiene no con una ubicación cómoda en la sociedad musulmana que se ha articulado en torno a un discurso del «Profeta» que es un canto de satisfacción por haber dejado a su pueblo una religión y un modelo de sociedad «perfectas» (Epalza, 1983, p. 145).

Así pues, con esta pretensión de ser el mejor sistema de vida, el musulmán se 
tiene que enfrentar al hecho, frustrante por un lado pero especialmente incoherente para su visión del mundo, de que el esplendor político y social no brille ni esté ahora en manos de la sociedad islámica. Los movimientos islamistas creen responder a esta crisis, primeramente con la negación y el rechazo de la modernización occidental a través de la denuncia profética (Informe del Ministerio español de Asuntos Exteriores al Consejo de Ministros de la C.E.C. Marzo 1992, ABC, 26-4-92). Y por otro mediante la constitucion de un contra-modelo de sociedad que llevaría a estas sociedades a rechazar con fuerza a los gobiernos que no sigan los valores fundamentales del Islam (Chevalier, J. J., 1989, p. 8). Se trataría, como afirma Bruno Etienne, de «islamizar la modernidad», si bien, como señala Lamchichi, hay profundas debilidades en su contramodelo que no pasarían, a juicio de este autor, del umbral de las «doctrinas de combate» o de las puras ideologías de rechazo frente a los efectos perversos del modelo occidental.

Si quisiéramos resumir brevemente las causas fundamentales de la aparición y expansión de estos movimientos políticos de raiz islámica habría que buscarlas en:

1) El rechazo masivo de la población fuera de las esferas de producción.

2) La ausencia de instituciones políticas de integración y de canalización democrática de los conflictos y

3) El sentmiento de pérdida de la identidad cultural, nacional o religiosa (Lamchichi, 1989, p. 44). 


\section{BIBLIOGRAFÍA}

AKSABI: L'etat moracain pris entre les imperatives de la regulation et les exigences de l' extraversion, A. A. du NOrd, 1984.

BALleSTEROS, J.: Postmodernidad, decadencia o resistencia, Tecnos, 1989.

BORWN KENNETH: Los cambios de las formas de patronazgo en una ciudad marroquí. VV.AA. Patronos y clientes, Júcar, 1986.

CARRE OLIVIER: Revue Francaise de Sciencie Politique, no 4, 1988.

CIDOB: Anuario Internacional, 1989 y 1990.

CHALINE CLAUDE: Les villes du monde arabe, a990.

CHEVALIER, J. J.: Introducción a Islam et contestation au Magrheb, París, L'harmatan, 1989.

DEL PINO, D.: Revista Política Exterior, no 25, p. 16.

DOBRY MICHEL: Les Avatars de la Modernization, 1990, p. 256, en Connaisances du Politique, PUF.

ETIENNE BRUNO: El clientelismo en Argelia. VV.AA. Patronos y Clientes, Júcar Universidad, 1986.

FERNÁNDEZ CARVAJAL, R.: Temas de Ciencia Política, Mimeo, Facultad de Derecho, Universidad de Murica, 1991, p. 24.

FLORY, M.: Les regimenes Politiques des Pays arabes, 1962, p. 131.

Problematique institutionelle de l'unité magrebine. A. du Afrique du Nord, 1970, p. 158.

GARCÍA GÓMEZ, E.: El arte dormido, ABC, 31-V-1992.

GELLNER, E.: VV.AA. Patronos y Clientes, Júcar Universidad, 1986, p. 13.

HERMASSI: Le Nouvel Etat et les resistences de la Societé Civil. A. du Afrique du Nord, 1983.

HOLTY TURNER:Las bases políticas del desarrolloeconómico, Fundación Foessa, Madrid, 1973.

IMNERARITY, D.: Dialéctica de la Modernidad, Rialp, 1990, p. 230.

JALAF SAMIR: Nuevas formas de patronazgo político en el Líbano. VV.AA. Patronos y Clientes, Júcar Universidad, 1986.

JUAN PABLO II: Centesimus Annus, BAC, 1991, p. 57.

LAMCHICHI: Islam et contestation au Magrheb, París, L'harmatan, 1989.

LEWIS, B.: Lenguaje político del Islam, Taurus, 1990, p. 14.

LÓPEZ GARCÍA, B.: Introducción a los regímenes y Constituciones árabes, C.E.R., 1985.

LÓPEZPINA, A.: Ideología y realidad de la Modernización, Vol. Homenaje a carlos Ollero, Madrid, 1972.

LUCAS MARÍN, A.: Razón y Sociedad, Ibérico Europea de Ediciones, 1992. 
MASMOUDI, M.: Les arabes dans la Tempete. A. du Afrique du Nord, 1970.

MOORE, Clement $\mathrm{H}$.: Ideología clientelística y cambio político: redes ficticias en Egipto y Tunicia. VV.AA.: Patronos y Clientes, Júcar Universidad, 1986.

NAIR SAMI: Connaisances du politique, PUF, 1990.

SANTUCCI: Le grandMaghreb reactivé.Crisis de Etats et ideologie de sustitution, A. du A. du Nord, 1983.

SCHIMDT, H.: Política Exterior, nº 19, 1991.

SILVERMAN: El patronazgo como mito, en VV.AA.: Patronos y Clientes, Júcar Universidad, 1986.

STEIMBACH, Udo: Análisis de ABC. El mundo islámico, 23-2-1992.

TORTOSA, J. M.: La identidad como problema, en El nacionalismo europeo, Proceno, 1992.

ZGHAL, A.: Pour quoi la Réforme Agraire ne mobilise-t-elle pas les paysans maghrebins?, A. du Afrique du Nord, 1975. 